\title{
Sistema de apoio à decisão na realização e no acompanhamento do teste da linguinha
}

\author{
Hitalo Emanoel Gondim Bezerra de Medeiros ${ }^{1}$ \\ Cicília Raquel Maia Leite ${ }^{1}$ \\ Jomar Ferreira dos Santos ${ }^{1}$ \\ Pedro Fernandes Ribeiro Neto ${ }^{1}$ \\ Roberta Lopes de Castro Martinelli ${ }^{2}$ \\ Renata Veiga Andersen Cavalcanti ${ }^{3}$
}

\begin{abstract}
Resumo: Entre os testes da triagem neonatal mais comuns tem-se: orelhinha, olhinho, pezinho, coraçãozinho e linguinha, em que são avaliadas as condições auditiva, visual, sanguínea, de saturação de oxigênio e de movimentação da língua, respectivamente. O contexto deste trabalho refere-se ao teste da linguinha, que verifica se o recém-nascido consegue movimentar corretamente a língua, pois se houver algo obstruindo essa movimentação, o bebê apresentará dificuldades nas funções que ela exerce (engolir, sugar, falar, mastigar, etc.). Sabe-se que identificar problemas na movimentação da língua não é fácil, assim, o auxílio de sistemas computacionais e de processamento inteligente das informações contribuiriam muito para acompanhar e dar suporte aos profissionais de saúde responsáveis pelo teste. Com isso, este trabalho tem como objetivo desenvolver um sistema de apoio à decisão na realização e no acompanhamento do teste da linguinha, utilizando redes neurais artificiais para emissão de alertas e recomendações em situações anormais. Destaca-se que, na concepção da rede neural artificial, foi utilizada uma base de dados criada por meio de protocolos reais fornecidos pelos especialistas que acompanharam o trabalho. Os resultados apresentados foram considerados satisfatórios e relevantes por médicos especialistas, principalmente pelas possibilidades de melhoria no atendimento dos recém-nascidos que pode ser propiciado pelo uso do sistema.
\end{abstract}

Palavras-chave: Assistência neonatal. Redes neurais artificiais. Sistema de apoio à decisão.

\begin{abstract}
Among the most common newborn screening tests we have: ears, eyes, blood, heart and tongue, which evaluates hearing condition, visual condition, blood condition, oxygen saturation and tongue movement, respectively. The context of this work will be the tongue test where it is important to check that the newborn can properly move his tongue, as if he has something obstructing this movement, will present difficulties in the functions which it exercises (swallowing, sucking, talking, chewing, etc.). It is known that identify problems with tongue movement it is not easy, so the aid of computer systems and intelligent processing of information would be a great contribution on attendance and support to health professionals responsible for the test. Thus, this work aims to develop a system for decision support in the implementation and monitoring of tongue test, using artificial neural networks to emit warnings and recommendations in abnormal situations. It is noteworthy that in the design of the artificial neural network was used a database created by actual protocols provided by the experts who accompanied the work. The results were
\end{abstract}

\footnotetext{
${ }^{1}$ Programa de Pós-Graduação em Ciência da Computação, Universidade do Estado do Rio Grande do Norte, campus central, Mossoró, RN, Brasil

\{hitalo.emanoel@gmail.com; ciciliamaialuern.br; jomarferreira.s@gmail.com; pedrofernandes@uern.br\}

${ }^{2}$ Hospital Santa Therezinha, Brotas, SP, Brasil

\{robertalcmegmail.com\}

${ }^{3}$ Universidade Federal do Rio Grande do Norte, Natal, RN, Brasil

\{rva.cavalcanti@gmail.com\}
}

http://dx.doi.org/10.5335/rbca.2015.5729

Revista Brasileira de Computação Aplicada (ISSN 2176-6649), Passo Fundo, v. 8, n. 1, p. 104-113, abr. 2016104 
considered satisfactory and relevant by medical experts, especially by the possibilities of improvement in the care of newborns that can be afforded by the use of the system.

\section{Keywords: Neonatal care. Artificial neural networks. Decision support system.}

\section{Introdução}

A evolução das Tecnologias da Informação e Comunicação (TIC) permite significativos avanços tecnológicos em diversas áreas, como em educação, saúde, economia, entretenimento ou segurança. Na área da saúde, pode-se destacar a concepção, o desenvolvimento e o aperfeiçoamento de equipamentos e/ou sistemas modernos que proporcionam à população inúmeros benefícios na busca de uma melhor qualidade de vida.

A combinação entre mobilidade e comunicação sem fio oferece aos usuários em movimento uma gama de serviços atraentes e de alta qualidade. Pois, juntamente com o avanço dos telefones celulares, as redes sem fio tornaram-se mais eficientes mediante o vasto número de aplicativos e informações que necessita ser processado e armazenado [1]. O desenvolvimento tecnológico está se deslocando rumo a um conjunto de serviços posicionados entre as telecomunicações e as TICs [2]. Tais serviços podem ser utilizados, por exemplo, para melhorar os índices da mortalidade infantil.

Mortalidade infantil é definida pela Organização Mundial de Saúde como morte infantil que ocorre até 28 dias após o nascimento [3]. Nas últimas décadas, nos países em desenvolvimento, a velocidade da redução dos índices está desacelerando, despertando preocupação nos governos e nas instituições voltadas ao bem-estar infantil, o que leva ao desenvolvimento de pesquisas e estratégias para o alcance de indicadores mais animadores. No Brasil, entre 1990 e 2000, a mortalidade infantil caiu de 47,1 para 26,8 óbitos em menores de um ano para cada mil nascidos vivos, a partir de então, observa-se uma desaceleração, chegando a 19,3 no ano de 2007 [4]. A taxa de mortalidade infantil reflete os efeitos das condições econômicas e sociais de saúde de mães e recém-nascidos bem como a eficiência dos sistemas de saúde [5]. Uma estratégia que atua na redução de complicações em recém-nascidos no período neonatal é a aplicação dos exames neonatais.

Exames neonatais são realizados no recém-nascido como forma de avaliação geral de saúde e para o diagnóstico precoce de doenças, permitindo começar cedo o tratamento e diminuindo, ou eliminando, possíveis fatores que possam prejudicar o desenvolvimento normal da criança. Entre os exames mais comuns estão os testes do pezinho, do olhinho, do coraçãozinho, da linguinha e da orelhinha. Cada um desses testes procura avaliar aspectos que auxiliem a identificar algum fator que possa comprometer a saúde da criança. $\mathrm{O}$ teste da linguinha, por exemplo, avalia a existência de alguma alteração na estrutura da língua da criança, como a anquiloglossia, ou língua presa, que se refere a um problema congênito caracterizado por uma anomalia no frênulo lingual que pode limitar a movimentação da língua. Essa limitação pode causar problemas para sugar, engolir e, posteriormente, mastigar e falar. Em bebês, pode causar cansaço para mamar e fazer com que eles abandonem a amamentação materna precocemente [6].

$\mathrm{Na}$ realização do teste da linguinha, vários dados são coletados. Um fator importante a ser observado é a natureza e a forma como esses dados são coletados (de forma manual em prontuários de papel), e como se dá o seu armazenamento (empilhados em gavetas em determinado espaço físico), fatores que implicam diretamente na disponibilidade, dificultando o acesso e a pesquisa das informações.

É possível utilizar sistemas computacionais para dar suporte e auxiliar profissionais de saúde em ambientes hospitalares. Esses sistemas tornam-se ainda mais eficientes se aplicados em conjunto com alguma técnica inteligente, tais como lógica fuzzy, redes neurais artificiais, redes bayesianas, etc. As redes neurais artificiais, por exemplo, garantem uma ferramenta significativa para ajudar médicos a analisar, modelar e esclarecer dados clínicos complexos por meio de uma ampla gama de aplicações [7].

Diante das dificuldades de armazenamento, inerentes ao acompanhamento e à execução do teste da linguinha, bem como o desenvolvimento de métodos para o pré-diagnóstico, a utilização de técnicas baseadas em sistemas inteligentes é essencial, porque, quando utilizadas em conjunto, podem colaborar na obtenção de bons resultados de diagnóstico.

Dessa forma, este trabalho apresenta o desenvolvimento de um sistema de apoio à decisão na realização e no acompanhamento do teste da linguinha utilizando redes neurais artificiais. Assim, a utilização de técnicas 
inteligentes na execução do teste faz com que os dados gerados sejam processados de forma automática e, assim, possam inferir automaticamente um pré-diagnóstico, gerando alertas em situações fora do padrão e disponibilizando-os para os profissionais de saúde.

Este trabalho está organizado como segue: na seção 2, é apresentada a fundamentação teórica do trabalho, na seção 3, é apresentado o desenvolvimento do sistema de apoio à decisão na realização e no acompanhamento do teste da linguinha, na seção 4, são demonstrados a validação e os resultados do sistema. Por fim, na seção 5 , são apresentadas as conclusões e a sugestão de trabalhos futuros.

\section{Fundamentação teórica}

\subsection{Trabalhos relacionados}

Na literatura, é possível encontrar vários trabalhos que visam ao desenvolvimento de soluções tecnológicas para dar suporte aos cuidados com recém-nascidos. Em [8], foi analisada a viabilidade de utilizar escaneamento ultrassom 3D para visualizar os movimentos da língua e verificar se os movimentos peristálticos da língua podem ser observados durante a amamentação. Para isso, quinze crianças saudáveis, entre dias, semanas e quatro meses de idade, foram escaneadas durante a amamentação utilizando um sistema tempo real de ultrassom 3D. O método mostrou-se viável, com $72 \%$ dos conjuntos de dados biplano e $56 \%$ dos conjuntos de dados $3 \mathrm{D}$ em tempo real, fornecendo cobertura adequada ( $>75 \%$ ) da língua infantil.

Em [9], foi desenvolvido um sistema web baseado em uma arquitetura multi-tier na realização de operações especiais e de rotina em unidades de cuidados intensivos neonatais (do inglês neonatal intensive care unit NICU). Esse sistema dispõe de várias tarefas cujo objetivo é gerenciar as atividades nessas unidades. O protótipo do sistema foi instalado no departamento de neonatologia do SSKM Hospital, Kolkata, Índia, e o pessoal do hospital, incluindo médicos, enfermeiros, membros de laboratório e técnicos, passou a usá-lo de forma regular.

Em [10], apresenta-se um equipamento para monitoramento neonatal, que se consiste de uma jaqueta inteligente composta por sensores que captam as informações relacionadas à saúde do recém-nascido. A jaqueta inteligente visa fornecer monitoramento de saúde de confiança bem como um ambiente clínico confortável para o cuidado neonatal e a interação entre pais e filhos.

Em [11], utilizou-se uma aplicação da tecnologia de sensores sem fio no cuidado neonatal e no monitoramento em unidade de terapia intensiva (UTI) neonatal. Foram incorporados nos sistemas de sensores sem fio um leitor de eletrocardiograma e um módulo transceptor sem fio desenvolvido pelo International Medical Equipment Collaborative (IMEC), no Centro de Holst, Holanda. O sistema sem fio foi projetado para ser integrado de forma não invasiva em plataforma de monitoramento, como uma jaqueta neonatal inteligente desenvolvida na Universidade de Tecnologia de Eindhoven, Holanda.

Em [12], há a proposta de uma interface homem-máquina que utiliza uma máquina de vetor de suporte para classificar a condição de saúde de recém-nascidos em unidades de cuidados intensivos neonatais por meio de um índice de prognóstico proposto no trabalho. Foram utilizadas técnicas de processamento, fusão e mineração de dados para classificar a condição de saúde dos recém-nascidos em alto risco, moderado, baixo risco ou ausência de risco.

Em [13], foi desenvolvido um sistema de medição de temperatura remoto de baixo custo, visando ao cuidado neonatal. Esse sistema, baseado em fluorescência, evita o uso de adesivos na pele do recém-nascido e, assim, o risco de descamação da epiderme ou infecção microbiana. Um algoritmo minimalista usando soma e divisão de pixels para computar uma relação é apresentado, adequado para aplicação em um sistema embutido mínimo.

Em [14], foi apresentada uma bomba de seringa para ser usada em hospitais de baixos recursos. O sistema foi possível devido à seringa ser de baixo custo, apresentar uma interface simples com o usuário e funcionar independente de energia elétrica, ao contrário das bombas de seringas tradicionais, que têm valor elevado e requerem técnicos treinados para seu manuseio. Além disso, essa opção apresentou uma taxa de erro inferior a $15 \%$ nos testes, e mostrou-se uma opção viável como método utilizado em terapia neonatal.

Em [15], pesquisou-se sobre desafios, tendências e oportunidades para o apoio em tempo real à decisão clínica neonatal integrada. Foi utilizado o ambiente conhecido como Artemis, um sistema de apoio à decisão 
clínica, que oferece suporte simultâneo multipaciente, multidiagnóstico, análise temporal multistream e aquisição de dados em tempo real a partir de vários monitores dentro de uma UTI neonatal. Uma revisão dos dispositivos atuais utilizados na UTI neonatal mostrou o ambiente atual e as perspectivas futuras dos autores para o apoio à decisão clínica neonatal. $\mathrm{O}$ estudo demonstrou que o sistema Artemis é capaz de incorporar novos fluxos de dados a partir de bombas de infusão, monitores de eletrocardiogramas e monitores de oxigenação cerebral, inovando a prática e melhorando o suporte clínico.

\subsection{Teste da linguinha}

O teste da linguinha é uma técnica pioneira, desenvolvida no Brasil pela fonoaudióloga Roberta Martinelli, para diagnóstico das alterações do frênulo lingual em bebês, popularmente conhecidas como língua presa. Seu objetivo é diagnosticar e tratar precocemente as limitações dos movimentos da língua causadas pela língua presa que podem comprometer as funções exercidas pela língua: sugar, engolir, mastigar e falar [16].

O teste consiste em avaliar uma série de fatores (antecedentes, amamentação, suç̧ão, etc.) que irão determinar se a criança deve ou não ser submetida à cirurgia. Cada característica avaliada gera uma pontuação que é utilizada para definir o resultado final do teste. A aplicação do teste da linguinha nas maternidades do Brasil tornou-se medida obrigatória assegurada pela Lei $n^{\circ}$ 13.002/2014 [17].

Bebês com problemas na língua podem apresentar dificuldade de sucção, o que pode afetar tanto o bebê e quanto a mãe. Os problemas mais percebidos incluem dificuldades na pegada (incluindo sinais de frustração como chacoalhar a cabeça), dor no peito materno (incluindo hemorragias, mamilos rachados ou ulcerados) e sinais de insatisfação por parte do bebê, como a amamentação frequente ou contínua geralmente com agitação [18].

O frênulo é uma prega de membrana mucosa situada na parte inferior da língua que pode limitar os movimentos do órgão [19]. A Figura 1 exemplifica frênulos que podem estar prejudicando a movimentação da língua em bebês.

Figura 1: Frênulo da língua em bebês [19]

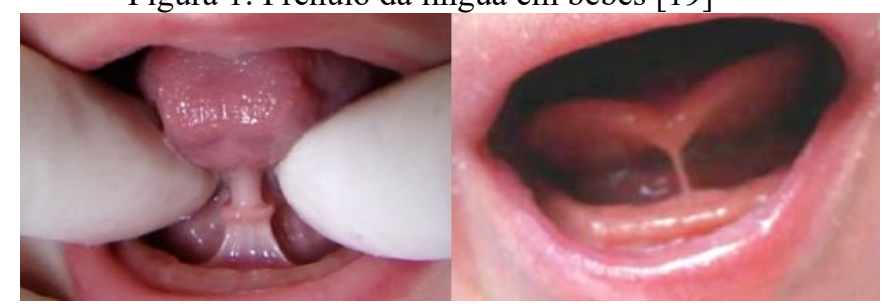

Fonte: Autoria Própria

A anquiloglossia, ou língua presa, refere-se a tecido frenular sublingual excessivo resultante da separação incompleta da língua do assoalho da boca durante a embriogênese [20]. A incidência desse diagnóstico é relatada como sendo entre $1,9 \%$ e 4,8\%, com uma prevalência maior em homens do que em mulheres, com uma taxa de 2,6 para 1 [21]. Se confirmada a alteração no frênulo, o recém-nascido é submetido à frenotomia (cirurgia de correção para esse caso).

Diagnosticar alterações do frênulo pode ser difícil pelo fato de o avaliador ter de conhecer de modo bastante aprofundado a anatomia da língua, assim como os diferentes aspectos do frênulo e das regiões adjacentes, para poder diferenciar normalidade e alteração [22].

\section{Sistema de apoio à decisão na realização e no acompanhamento do teste da linguinha}

Foi desenvolvido um sistema de apoio à decisão na realização e no acompanhamento do teste da linguinha utilizando redes neurais artificiais e redes bayesianas. Assim, a utilização de técnicas inteligentes na execução do teste permite que os dados gerados sejam processados de forma automática e, assim, possam inferir automaticamente um pré-diagnóstico, gerando alertas em situações fora do padrão e disponibilizando-os para os profissionais de saúde. O sistema foi nominado T_Linguinh@. No desenvolvimento do sistema, foram utilizadas 
técnicas de inteligência computacional, visando ao processamento e à classificação dos dados de entrada bem como à geração de informações úteis (pré-diagnósticos na forma de indicadores visuais).

Dentre as principais características e funcionalidades apresentadas pelo sistema, tem-se: a) identificação e análise dos dados oriundos dos protocolos do teste da linguinha; b) seleção dos dados oriundos dos protocolos do teste da linguinha a serem utilizados no processamento; c) processamento dos dados oriundos dos protocolos do teste da linguinha; d) geração de alertas e persistência das informações.

Foi desenvolvida uma rede neural artificial (RNA) para o processamento dos dados. Os dados selecionados para servir como entrada para a rede neural são aqueles que contabilizam na pontuação final do teste realizado atualmente.

Com isso, tem-se que a entrada da RNA é composta pelos seguintes atributos: antecedentes familiares, intervalo entre as mamadas, cansaço para mamar, mama e dorme, soltando mamilo, morde mamilo na amamentação, postura dos lábios em repouso, tendência do posicionamento da língua durante o choro, forma da ponta da língua quando elevada durante o choro ou manobra de elevação, espessura do frênulo, fixação do frênulo na face sublingual (ventral) da língua, fixação do frênulo no assoalho da boca, movimento da língua, ritmo da sucção, coordenação entre sucção/deglutição/respiração, morde o mamilo durante a sucção, produz estalos de língua durante a sucção.

O sistema funciona com as seguintes etapas:

a) aquisição dos dados mediante o registro em uma das plataformas desenvolvidas no trabalho;

b) pré-processamento, no qual são realizadas a preparação (filtragem) e a seleção dos dados;

c) processamento dos dados e classificação do frênulo (normal ou alterado) por meio da RNA;

d) pós-processamento, com as conclusões do processo inteligente e recomendações ao profissional de saúde.

O processo de aquisição do conhecimento foi realizado de três formas: em estudo da literatura médica sobre o teste da linguinha e como se processa a avaliação; em reuniões e discussões com profíssionais da área que acompanharam o desenvolvimento deste trabalho e, por fim, com a extração e análise dos dados obtidos durante o teste da linguinha nas consultas realizadas no Hospital Santa Therezinha, São Paulo.

Os dados armazenados no banco de dados do sistema foram obtidos nos protocolos do teste da linguinha registrados durante as consultas realizadas no hospital, constituindo um conjunto de dados padrão-ouro, ou seja, com confirmação de normalidade ou alteração do frênulo.

A base de dados foi gerada em 2015, com 186 registros de consultas de pacientes de diagnósticos conhecidos (sendo 148 com frênulo normal e 38 com frênulo alterado), cada registro contém informações, como antecedentes, dados da amamentação, dados anatomofuncionais e de sucção não nutritiva e nutritiva. Os dados de entrada são processados e classificados em normal ou alterado. Esse processo é realizado por meio da rede neural desenvolvida neste trabalho.

A rede neural deste trabalho foi desenvolvida utilizando a biblioteca Weka [23], uma plataforma de mineração de dados baseada em Java e com código fonte aberto, que tem vários algoritmos de aprendizagem de máquina para minerar dados, incluindo pré-processamento de dados, classificação, cluster, regras de associação e páginas visuais interativas [24].

A rede desenvolvida, ilustrada na Figura 2, é uma rede supervisionada de multicamadas, com o algoritmo backpropagation e função sigmoide para ativação. A rede conta com dezoito atributos de entrada, treze neurônios na camada intermediária e dois na camada de saída. Ao final do processamento, a rede indica, de acordo com os dados de entrada, se o frênulo está normal ou não. 
Figura 2: RNA para classificar o frênulo da língua

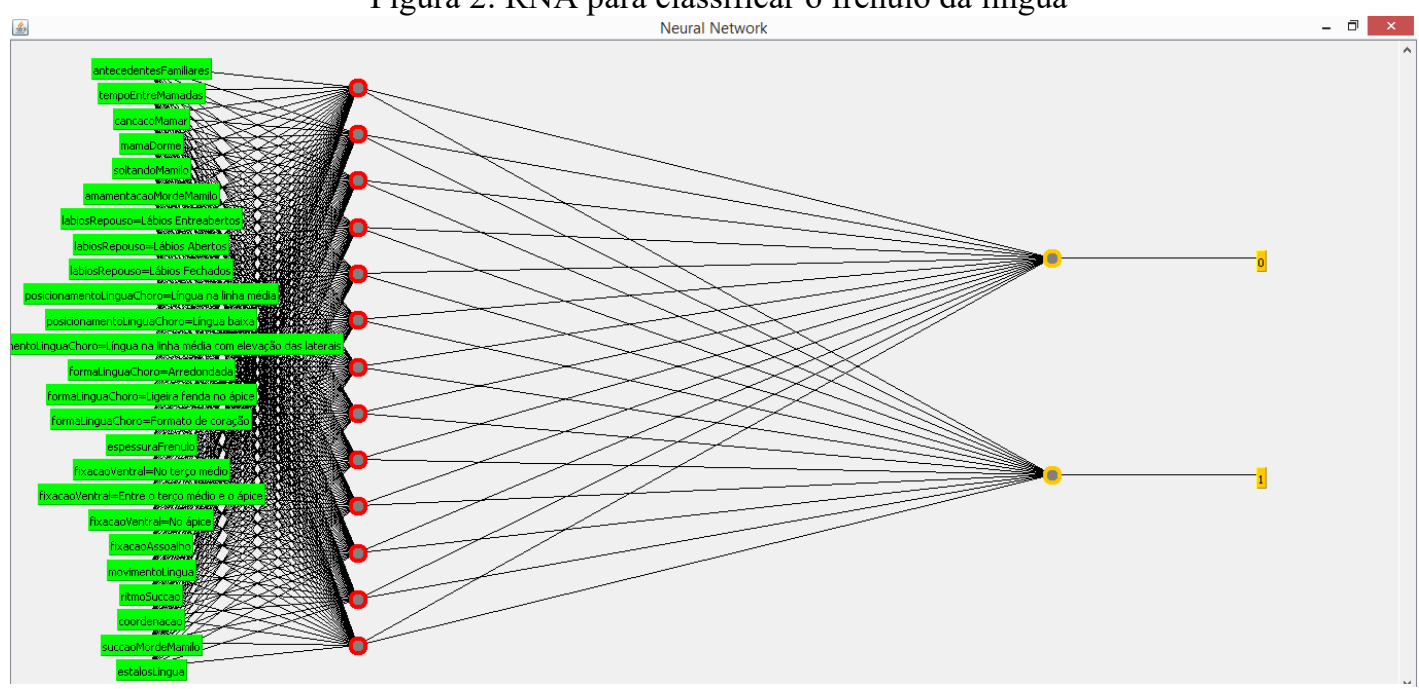

Fonte: Autoria Própria.

A RNA pode ser acessada por meio do T_Linguinh@, que foi desenvolvido neste trabalho e constitui-se em uma importante ferramenta de auxílio nas rotinas do teste da linguinha, possibilitando o cadastro dos dados do recém-nascido, bem como dos dados gerados no decorrer do acompanhamento do teste, selecionando e classificando os dados inseridos, gerando pré-diagnóstico (frênulo normal ou alterado) e emitindo alertas, contribuindo, assim, com o diagnóstico e a tomada de decisão. O T_Linguinh@ tem versões para dispositivos móveis (Figura 3) e para web.

O T_Linguinh@Web é um ambiente on-line que visa possibilitar um amplo acompanhamento do teste de recém-nascidos. Para isso, possibilita, de modo simples e intuitivo, o registro e o acesso às informações. $\mathrm{O}$ T_Linguinh@ Móvel, por sua vez, é um ambiente móvel que permite a seleção, o processamento e a classificação dos dados de entrada além de possibilitar o registro e acesso às informações.

Figura 3: T_Linguinh@, Móvel

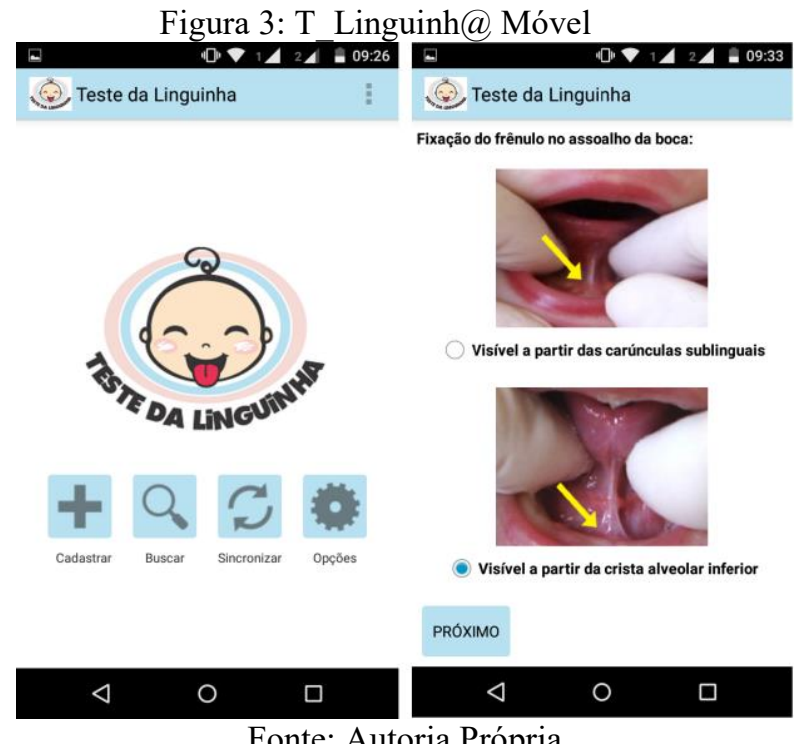

Fonte: Autoria Própria

Dentre as contribuições do desenvolvimento deste trabalho, destacam-se:

a) desenvolvimento de um módulo móvel inteligente para aplicação do protocolo da linguinha, fornecendo pré-diagnóstico para auxiliar profissionais de saúde; 
b) desenvolvimento de uma RNA capaz de receber dados do sistema, processá-los e retornar o resultado desse processamento;

c) armazenamento do histórico de pacientes no contexto do protocolo referente ao teste da linguinha;

d) criação de um banco de dados padrão-ouro referente ao protocolo do teste da linguinha.

\section{Validação e resultados}

Os testes do sistema foram realizados utilizando-se a ferramenta Weka (versão 3.7.3), devido aos algoritmos disponíveis na ferramenta, possibilitando a criação de modelos e a rápida visualização dos resultados. Para a validação foram utilizados os 186 registros do banco de dados gerado no trabalho. Vale ressaltar que o banco de dados foi criado com registros reais dos pacientes do teste, e que o resultado do frênulo (normal ou alterado) de cada registro foi validado por médicos especialistas.

Os 186 casos foram processados pela RNA, e o resultado foi então comparado com o resultado da avaliação médica. Como é possível observar na Figura 4, apenas um caso (representado por quadrado) divergiu do esperado, os outros 185 (representados por $\mathrm{X}$ ) foram compatíveis com o resultado da avaliação por pontos.

Figura 4: Gráfico de resultado da classificação da RNA

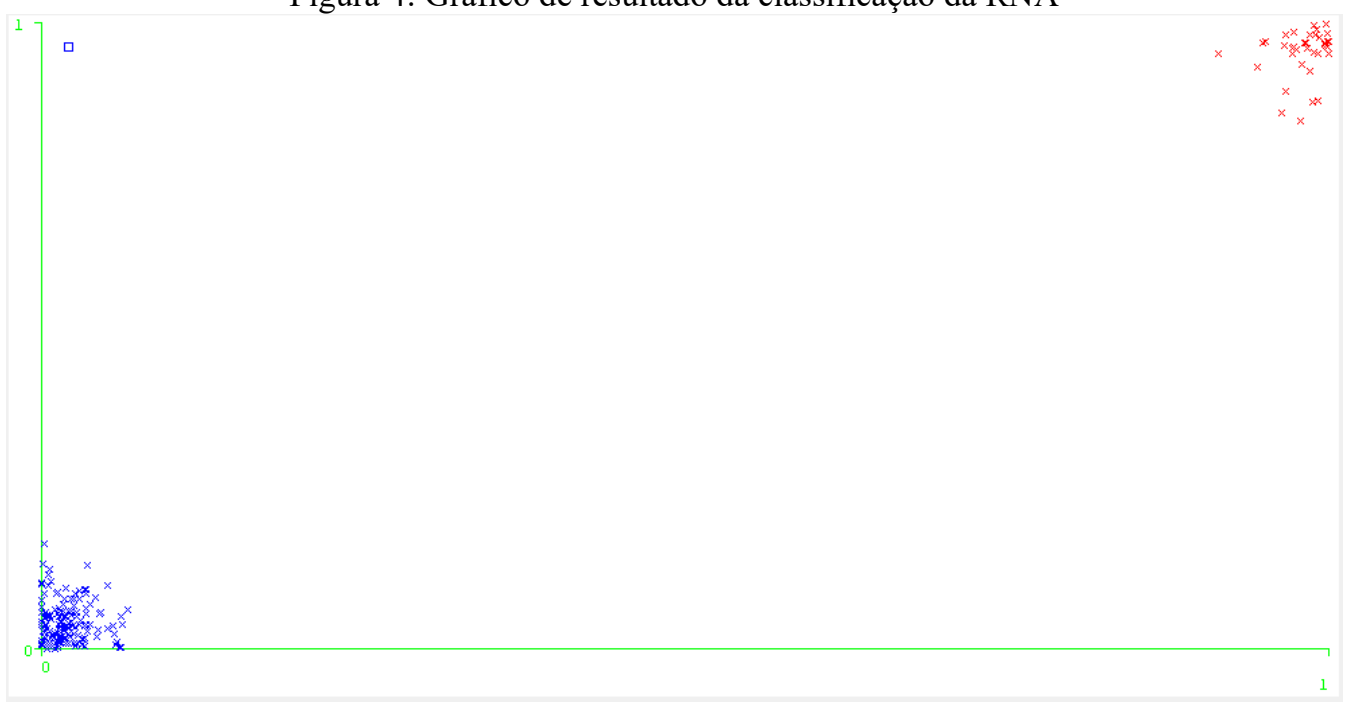

Fonte: Autoria Própria.

A Figura 5 ilustra a matriz de confusão do processamento. Podemos observar que, dos 148 casos que deveriam ser classificados como normais (representado por a), a RNA classificou 147 como normais e 1 como alterado (representado por b). A RNA acertou os 38 casos classificados como alterados.

Figura 5: Matriz de confusão da RNA

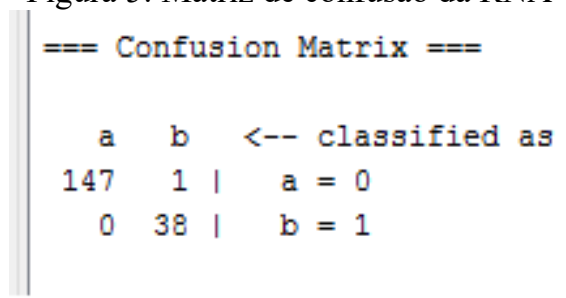

Fonte: Autoria Própria.

Seguindo esse mesmo raciocínio, outros ensaios, variando o número de registros utilizados no treinamento e no teste, foram criados. A Tabela 1 apresenta as quantidades de registros utilizados no treino, registros utilizados no teste, registros classificados como normal no teste, registros classificados como alterado no teste, registros classificados corretamente como normal pela RNA, registros classificados corretamente como alterado pela RNA e o índice de acerto da RNA. 
Tabela 1: Resultado dos ensaios

\begin{tabular}{|c|c|c|c|c|c|c|c|}
\hline & $\begin{array}{c}\text { Registros } \\
\text { para } \\
\text { treino }\end{array}$ & $\begin{array}{c}\text { Registros } \\
\text { para } \\
\text { teste }\end{array}$ & Normal & Alterado & $\begin{array}{l}\text { Classificado } \\
\text { corretamente } \\
\text { como normal }\end{array}$ & $\begin{array}{c}\text { Classificado } \\
\text { corretamente } \\
\text { como } \\
\text { alterado }\end{array}$ & $\begin{array}{l}\text { Índice } \\
\text { de } \\
\text { acerto }\end{array}$ \\
\hline Ensaio 1 & 100 & 186 & 148 & 38 & 147 & 38 & $99,46 \%$ \\
\hline Ensaio 2 & 100 & 86 & 71 & 15 & 70 & 14 & $97,67 \%$ \\
\hline Ensaio 3 & 80 & 80 & 65 & 15 & 64 & 14 & $97,5 \%$ \\
\hline Ensaio 4 & 86 & 100 & 77 & 23 & 75 & 23 & $98 \%$ \\
\hline
\end{tabular}

Fonte: Autoria Própria

O índice de acerto da RNA foi considerado satisfatório pelos médicos especialistas, não apenas pelo alto grau de precisão, mas também por se manter constante (entre 97,5\% e 99,46\%) em todos os ensaios.

Por meio do sistema desenvolvido, a saída da RNA é interpretada e apresentada ao profissional. Como se observa na Tabela 2, existem três resultados: o resultado da avaliação do sistema de pontos (avaliação médica), o resultado da RNA e o resultado final.

Tabela 2: Possíveis resultados das avaliações

\begin{tabular}{cccc}
\hline Avaliação médica & Avaliação RNA & Avaliação final & Recomendação \\
\hline $\begin{array}{c}\text { Normal } \\
\text { Normal }\end{array}$ & Normal & Normal & Não há recomendações \\
Alterado & Normal & $\begin{array}{c}\text { Recomdável verificar } \\
\text { os dados }\end{array}$ \\
Alterado & Normal & Alterado & $\begin{array}{c}\text { Recomendável verificar } \\
\text { os dados } \\
\text { Alterado }\end{array}$ \\
& Alterado & Alterado & Não há recomendações \\
\hline \multicolumn{2}{c}{ Fonte: Autoria Própria }
\end{tabular}

O profissional responsável sempre tem a palavra final no diagnóstico, portanto, o resultado final sempre será igual ao resultado do sistema de pontos. Se o resultado da RNA for igual ao resultado do sistema de pontuação, tudo está dentro da normalidade, seja qual for o diagnóstico (normal ou alterado) e não há recomendações a serem feitas.

Porém, se o resultado da RNA for diferente do resultado do sistema de pontos, existe a possibilidade de que o profissional responsável pelo teste tenha cometido algum erro ao inserir algum dos dados no protocolo. Nesse caso, o sistema vai recomendar que o profissional revise os dados inseridos antes de definir o diagnóstico. Com isso, espera-se minimizar as falhas humanas que ocorreriam sem a utilização do sistema e maximizar a confiança no diagnóstico final do teste.

\section{Conclusão}

Este trabalho apresentou um sistema de apoio à decisão na realização e no acompanhamento do teste da linguinha utilizando redes neurais artificiais, que é capaz de classificar o frênulo da língua de bebês, emitindo alertas e recomendações em função de pré-diagnóstico realizado, auxiliando o diagnóstico médico.

O uso de redes neurais artificiais permitiu a avaliação dos dados de teste, o pré-diagnóstico, a emissão de alertas e recomendações aos profissionais de saúde, atendendo, assim, às expectativas que se tinha com a técnica em relação ao objetivo proposto.

A principal contribuição deste trabalho foi a especificação e implementação de um sistema de apoio, baseado em RNA e redes bayesianas, que atende às exigências para suporte e acompanhamento dos profissionais de saúde na execução do teste da linguinha, realizado a partir de dados reais e de contato com os especialistas médicos.

Além disso, destaca-se o desenvolvimento de um módulo para acesso ao sistema por meio de dispositivos móveis e de um módulo para acesso ao sistema por meio de navegadores web, a análise e validação dos dados 
inseridos, a modelagem e criação de uma rede neural artificial para análise e classificação de dados reais do teste da linguinha, a criação de um banco de dados reais relacionados ao teste da linguinha, o acesso remoto aos serviços disponibilizados e a utilização e validação do sistema desenvolvido no trabalho.

Como indicação de trabalhos futuros, sugere-se: treinamento e teste da RNA com uma quantidade maior de registros; levantamento estatístico da influência de cada variável do protocolo no resultado final do teste; emissão de relatório aos pacientes; desenvolvimento de um módulo destinado aos pacientes; ampliação do uso do sistema em ambiente real; implantação de módulo para monitoramento da utilização do sistema, gerando informações e estatísticas sobre uso, de modo a subsidiar a tomada de decisão dos gestores públicos com respeito aos investimentos e às intervenções voltadas ao teste da linguinha.

\section{Agradecimentos}

Agradecemos ao Grupo de Engenharia de Software da Universidade do Estado do Rio Grande do Norte e à Coordenação de Aperfeiçoamento de Pessoal de Nível Superior.

\section{Referências}

[1] DIAS, L. R. A revolução da mobilidade: o celular no brasil de símbolo de status a instrumento de cidadania. In: São Paulo: Plano Editorial. 2002.

[2] HEALTH, M. of. Perinatal Health Indicators for Canada : a Resource Manual. Minister of Public Works and Government Services Canada, 2000.

[3] OECD. In: EUROPE (Ed.). Infant mortality, in health at a glance. OECD Publishing, 2012.

[4] Ministério da Saúde e Organização Pan-Americana de Saúde. Manual AIDPI Neonatal. 3. ed. Ministério da Saúde, 2012. (Serie A. Normas e Manuais Técnicos).

[5] DONGARRA, J. et al. (Ed.). Sourcebook of Parallel Computing. San Francisco, CA, USA: Morgan Kaufmann Publishers Inc., 2003.

[6] HONG, P. et al. Defining ankyloglossia: A case series of anterior and posterior tongue ties. In: International Journal of Pediatric Otorhinolaryngology. San Diego, Elsevier Ireland Ltd, 74 (2010) 1003-1006, 2010.

[7] AL-SHAYEA, Q. K. Artificial neural networks in medical diagnosis. In: International Journal of Computer Science Issues. MIS Department, Al-Zaytoonah University of Jordan. Vol. 8, Issue 2, ISSN (Online) 16940814, Amman, Jordan, 2011.

[8] BURTON, P. et al. Real-time 3d ultrasound imaging of infant tongue moviments during breast-feeding. In: Early Human Development 89 (2013). London, 635-641, 2013.

[9] RAY, S. et al. A web enabled health information system for the neonatal intensive care unit (nicu). In: services (SERVICES), 2011 IEEE World Congress on Services. IEEE Computer Societty. Kharagpur, India. 2011. p. 451-458.

[10] BOUWSTRA, S. et al. Smart jacket design for neonatal monitoring with wearable sensors. In: Wearable and Implantable Body Sensor Networks, 2009. BSN 2009. Sixth International Workshop on. Einhhoven, Netherlands, 2009. p. 162-167.

[11] CHEN, et al. Design of wireless sensor system for neonatal monitoring. In: Mobility and Security (NTMS), 4th IFIP International Conference on. 978-1-4244-8704-2, IEEE. Einhhoven, Netherlands, 2011.

[12] AGARWAL, S.; PANDEY, G. Human computer interface design for neonatal intensive care with data mining. In: Intelligent Human Computer Interaction (IHCI), $20124^{\text {th }}$ International Conference on. IEEE Proceedings. Kharagpur, India, 2012. p. 1-6.

[13] CHATTERJEE, K. et al. Low-cost fluorescence-based temperature sensing system for neonatal care. In: SENSORS, 2013 IEEE. University of Maryland Baltimore Country, 1000 Hilltop Circle, Baltimore MD, 21250, 2013. p. 1-4. ISSN 1930-0395.

Revista Brasileira de Computação Aplicada (ISSN 2176-6649), Passo Fundo, v. 8, n. 1, p. 104-113, abr. 2016112 
[14] SUNG, C. et al. Design of a novel mechanical syringe pump for neonatal care in low-resource settings. In: Global Humanitarian Technology Conference (GHTC), 2011 IEEE 978-0-7695-4595-0. Rice University, Houston, Texas, 2011. p. 78-83.

[15] BRESSAN, N.; JAMES, A.; MCGREGOR, C. Trends and opportunities for integraded real time neonatal clinical decission support. In: Biomedical and Health Informatics (BHI) IEEE-EMBS International Conferênce. 2012.

[16] CAMPOS, P. R. J. et al. Atuação fonoaudiológica na atenção primária na saúde proposta para prefeitura municipal de Curitiba - PR. In: SEMINÁRIO NACIONAL DE PLANEJAMENTO E DESENVOLVIMENTO. Curitiba, Brasil. 2013.

[17] BRASIL. Lei 13.002, de 20 de junho de 2014. Disponível em: <http://www.planalto.gov.br/ccivil_03/_Ato2011-2014/2014/Lei/L13002.htm>. Acesso em: 1 out. 2014.

[18] BROOKES, A.; BOWLEY, D. M. Tongue tie: The evidence for frenotomy. In: Early Human Development 90 (2014). Heart of England NHS Foundation Trust, Bordesley Green East, Birmighan B9 5SS, United Kingdom, 2014. 765-768.

[19] MARTINELLI, R. L. de C.; MARCHESAN, I. Q.; BERRETIN-FELIX, G. Protocolo de avaliação do frênulo da língua para bebês: Relação entre aspectos anatômicos e funcionais. In: Rev. CEFAC. São Paulo, 2013.

[20] O'CALLAHAN, C.; MACARY, S.; CLEMENTE, S. The effects of office-based frenotomy for anterior and posterior ankyloglossia on breastfeeding. In: International Journal of Pediatric Otorhinolaryngology. Middletown, CT, United States, 2013. 827-832.

[21] GLYNN, R. W.; COLREAVY, M.; ROWLEY, H.; GENDY, S. Division of tongue tie: Review of pratice trought a tertiary paediatric otorhinolaryngology service. In: International Journal od Pediatric Otorhinolaryngology. Dublin, Ireland. 76 (2012) 1434-1436. 2012.

[22] MARCHESAN, I. Q. Protocolo de avaliação do frênulo da língua. In: Rev. CEFAC. 12(6): 977-989. 2010.

[23] WEKA. Weka 3: Data mining software in java. 2015. Disponível em: $<$ http://www.cs.waikato.ac.nz/ml/weka/>. Acesso em: 1 out. 2015.

[24] ZHONG, X. yu. The research and application of web log mining based on the platform weka. In: SciVerse ScienceDirect. [S.1.]: Advanced in Control Engineeringand Information Science, School of Computer Science, Jiaying University, Meizhou, Guangdong, China, 15 (2011) 4073-4078. 2011. 